\title{
An Application of DEA Windows Analysis to Container Port Production Efficiency
}

\author{
KEVIN CULLINANE \\ School of Marine Science \& Technology, University of Newcastle \\ DONG-WOOK SONG \\ Centre of Urban Planning and Environmental Management, The University of Hong Kong \\ PING JI \\ Department of Industrial and Systems Engineering, The Hong Kong Polytechnic University \\ TENG-FEI WANG \\ Department of Industrial and Systems Engineering, The Hong Kong Polytechnic University
}

\begin{abstract}
There have been various analyses of the efficiency of container port (or terminal) production using Data Envelopment Analysis (DEA) based on cross-sectional data. When time is not considered, the efficiency results derived using this approach can be biased. In order to overcome this problem, this paper applies DEA windows analysis, utilising panel data, to a sample of the world's major container ports in order to deduce their relative efficiency. The results suggest that estimates of container port efficiency fluctuate over time. The paper concludes that existing programming methods for estimating efficiency are inadequate in capturing the long-term increased efficiency and competitiveness that accrue from significant investments.
\end{abstract}

\section{Introduction}

The globalisation of the world economy has led to an increasingly important role for transportation. In particular, container transportation plays a key role in the process, largely because of the numerous technical and economic advantages it possesses over

* Corresponding Author. School of Marine Science \& Technology, Armstrong Building, University of Newcastle, Newcastle upon Tyne NE1 7RU, UK. Tel: +44 (0) 191222 6718, Fax: +44 (0) 191222 5491. Email: Kevin.Cullinane@ncl.ac.uk The authors wish to acknowledge Hong Kong Polytechnic University for providing the funding (Project No. G-T647) to support the research reported in this paper. The authors are grateful to Professor Wayne Talley and an anonymous referee for suggestions which have undoubtedly improved the paper. 
traditional methods of transportation. Standing at the crucial interface of sea and inland transportation, the significance of the container port and its production capabilities cannot be ignored.

Compared with traditional port operations, containerisation has greatly improved port production performance because of two reasons. To reap economies of scale and of scope, liner shipping companies and container ports are respectively willing to deploy dedicated container ships and efficient container handling systems. In so doing, port productivity has been greatly enhanced. On the other hand, many container ports no longer enjoy the freedom yielded by a monopoly over the handling of cargoes from within their hinterland; they are not only concerned, therefore, with whether they can merely physically handle cargo, but also whether they can compete for that cargo.

Under such a competitive environment, port performance measurement is not only a powerful management tool for port operators, but also constitutes a most important input for informing regional and national port planning and operations. Traditionally, the performance of ports has been variously evaluated by calculating cargo-handling productivity at berth (Bendall and Stent, 1987; Tabernacle, 1995; Ashar, 1997), by measuring a single factor productivity (De Monie, 1987) or by comparing actual with optimum throughput over a specific time period (Talley, 1998).

In recent years, significant progress has been made concerning the measurement of efficiency in relation to productive activities. In particular, non-parametric frontier methods have been developed with applications across a wide range of sectors including transit services. A recent work by De Borger, Kerstens and Costa (2002) claims that frontier models have found their way into the transport sector, and studies on the productivity and efficiency of almost all transport modes are appearing.

In this vein, Data Envelopment Analysis (DEA) is one of the most important approaches to measuring efficiency. Marlow and Paixão (2002) advocate that DEA should be used for port performance measurement and its suitability has been examined by Wang, Song and Cullinane (2002). There have also been several applications of DEA to the sea port industry: e. g. Tongzon (2001); Valentine and Gray (2001) and Martinez-Budria et al (1999). However, these applications are restricted to the application of standard DEA models such as the CCR (due to Charnes, Cooper and Rhodes, 1978) and BCC (due to Banker, Charnes and Cooper, 1984) models and to the use of cross-sectional data.

As stated by Kumbhakar and Lovell (2000, p.10), "Cross-sectional data provide a snapshot of producers and their efficiency. Panel data provide more reliable evidence on their performance, because they enable us to track the performance of each producer through a sequence of time periods". In order to overcome this potential problem associated with an analysis based on cross-sectional data, in this paper DEA windows analysis is, for the first time (to our knowledge), applied to the port industry to deduce efficiency trends. Annual panel data of twenty-five leading container ports from around the world are collected for the period 1992-1999, and the efficiency of these ports is analysed over time.

\section{Container port production measurement}

Performance measurement plays an important role in the development of a company (or any other form of organisational Decision Making Unit (DMU)). Dyson (2000) claims that 
performance measurement plays an essential role in evaluating production because it can define not only the current state of the system but also its future, as shown in Figure 1. Performance measurement helps move the system in the desired direction through the effect exerted by the behavioural responses towards these performance measures that exist within the system. Mis-specified performance measures, however, will cause unintended consequences, with the system moving in the wrong direction.

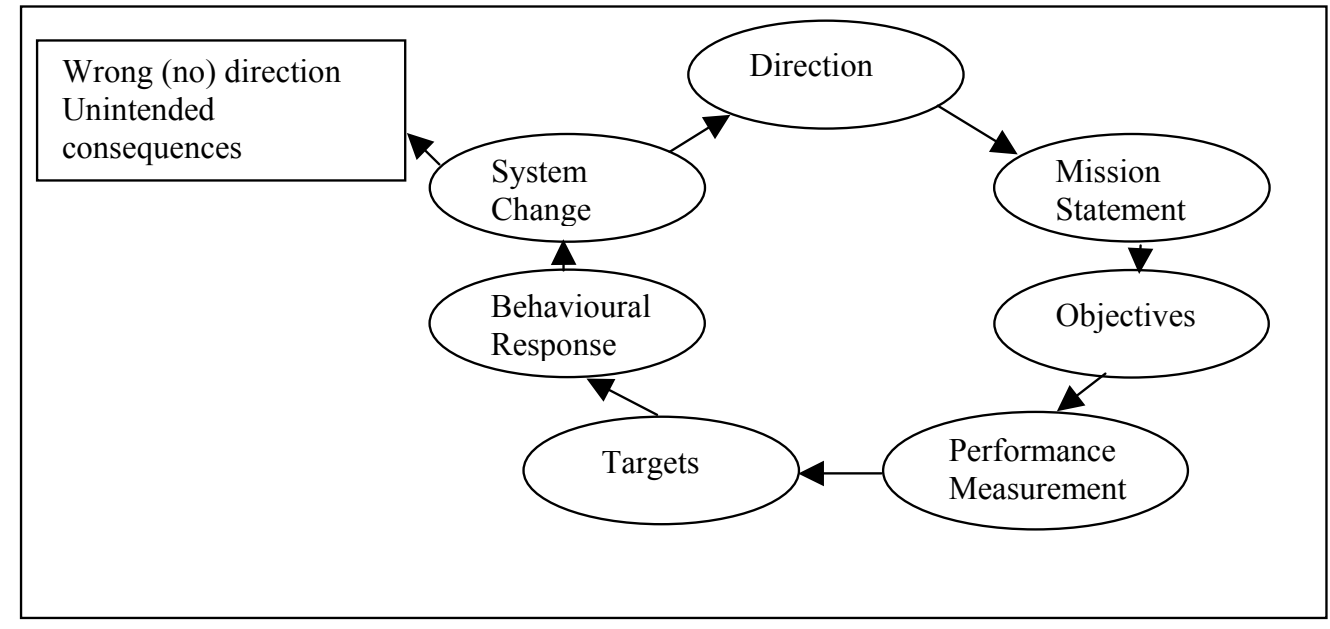

Figure 1: Performance measures and organisational development

Source: Dyson (2000, p. 5)

Ports are essentially providers of service activities, in particular for vessels, cargo and inland transport. As such, it is possible that a port may provide sound service to vessel operators on the one hand and unsatisfactory service to cargo or inland transport operators on the other. Therefore, port performance cannot normally be assessed on the basis of a single value or measure. The multiple indicators of port performance can be found in the example of the Australian port industry (Talley, 1994) and UNCTAD (1976).

Talley (1994) goes further by attempting to build a single performance indicator - the shadow price of variable port throughput per profit dollar - to evaluate the performance of a port. This overcomes the drawback of multiple indicators, that is examining whether port performance has improved or deteriorated becomes difficult when changes in some indicators improve performance and changes in others affect it negatively.

In an effort to more properly evaluate port performance, several methods have been suggested, such as the estimation of a port cost function (De Neufville and Tsunokawa, 1981) the estimation of the total factor productivity of a port (Kim and Sachish, 1986) and the establishment of a port performance and efficiency model using multiple regression analysis (Tongzon, 1995).

In recent years, DEA has occasionally been used to analyse port production. Compared with traditional approaches, DEA has the advantage that consideration can be given to multiple inputs and outputs. This accords with the characteristics of port production, so that there exists, therefore, the capability of providing an overall evaluation of port performance. 
Roll and Hayuth (1993) is probably the first attempt in this respect. However, this work should be treated as a theoretical exploration of applying DEA to the port sector, rather than as a genuine application. This is because no genuine data were collected and analysed.

Martinez-Budria et al (1999), classified 26 ports into three groups; namely, 'high complexity', 'medium complexity' and 'low complexity' ports. After examining the efficiency of these ports using DEA-BCC models, the authors conclude that the ports of 'high complexity' are associated with high efficiency, compared with the medium and low efficiency found in other groups of ports.

Tongzon (2001) uses both DEA-CCR and DEA-additive models to analyse the efficiency of 4 Australian and 12 other international container ports for the year 1996. Clearly plagued by a lack of data availability and the small sample size (only 16 observations), more efficient ports than inefficient ports are identified. Realising this serious drawback, the author suggests that further work should be done in collecting more observations to enlarge the sample analysed.

Valentine and Gray (2001) apply the DEA-CCR model to 31 container ports out of the world's top 100 container ports for year 1998. The objective of this work was to compare port efficiency with a particular type of ownership and organisational structure to determine any relationship with efficiency.

\section{DEA windows analysis}

DEA can be roughly defined as a nonparametric method of measuring the efficiency of a Decision Making Unit (DMU) with multiple inputs and/or multiple outputs. This is achieved by constructing a single 'virtual' output to a single 'virtual' input without predefining a production function. The term DEA and the CCR model were first coined in 1978 (Charnes, Cooper and Rhodes, 1978) and were followed by a phenomenal expansion of DEA in terms of its theory, methodology and application over the last few decades. The great influence of the CCR paper is reflected by the fact that it had been cited over 700 times by 1999 (Forsund and Sarafoglou, 2002).

Among other models in the context of DEA, the two most widely used DEA models, named DEA CCR and BCC models, deserve greater attention, especially since they are utilised later in this paper.

The DEA-CCR model assumes constant returns to scale so that all observed production combinations can be scaled up or down proportionally. The DEA-BCC model, on the other hand, allows for variable returns to scale and is graphically represented by a piecewise linear convex frontier.

Formally, let inputs be $x_{k}=\left(x_{1 k}, x_{2 k} \Lambda x_{M k}\right) \in R_{+}^{M}$ to produce outputs $y_{k}=\left(y_{1 k}, y_{2 k} \Lambda y_{N k}\right) \in R_{+}^{N}$. The row vectors $x_{k}$ and $y_{k}$ form the $k$ th rows of the data matrices $X$ and $Y$, respectively. Let $\lambda=\left(\lambda_{1}, \lambda_{2} \Lambda \lambda_{K}\right) \in R_{+}^{K}$ be a non-negative vector, which forms the linear combinations of the $K$ firms. Finally, let $e=(1,1, \ldots, 1)$ be a suitably dimensioned vector of unity values.

The output-oriented DEA model seeks to maximize the proportional increase in output while remaining within the production possibility set. An output-oriented efficiency measurement problem can be written as a series of $K$ linear programming envelopment 
problems, with the constraints differentiating between the DEA-CCR and DEA-BCC models, as shown in Equations (1) through (5).

(1) $\max _{U, \lambda} U$

Subject to

(2) $U y_{k}{ }^{\prime}-Y^{\prime} \lambda \leq 0$

(3) $X^{\prime} \lambda-x_{k}^{\prime} \leq 0$

(4) $\lambda \geq 0($ DEA-CCR)

(5) $\mathrm{e} \lambda^{\prime}=1($ DEA-BCC)

The combination of Equations from (1) through (4) and (1) through (5), respectively, form the DEA-CCR and DEA-BCC models. The output-oriented measure of technical efficiency of the $k$-th DMU, denoted by $T E_{k}$, can be computed by equation (6).

(6) $T E_{k}=1 / U_{k}$

It is important to note that input-oriented models can be formulated in a similar way. Interested readers may refer to Seiford and Thrall (1990), Ali and Seiford (1993) and Cooper, Seiford and Tone (2000) for more discussion on the above models.

The technical efficiency derived from DEA-CCR and DEA-BCC models are frequently used to obtain a measure of scale efficiency, as shown in equation (7) (Cooper, Seiford and Tone, 2000).

$$
S E_{k}=U_{C C R_{-} k} / U_{B C C_{-} k}
$$

$\ldots$ where $S E_{k}$, indicates scale efficiency and $U_{C C R_{-} k}$ and $U_{B C C_{-} k}$ are the estimated technical efficiency of DMU $k$ respectively derived from the DEA-CCR and DEA-BCC models. $S E_{k}$ $=1$ indicates scale efficiency and $S E_{k}<1$ indicates scale inefficiency.

Scale inefficiency is due to either increasing or decreasing returns to scale which can be determined by inspecting the sum of weights, $\mathrm{e} \lambda^{\prime}$, under the specification of the CCR model. If this sum is equal to one, the law of constant returns to scale prevails, whereas increasing returns to scale and decreasing returns to scale prevail when the sum is less than or greater than one.

DEA is initially used to analyze cross-sectional data, where a given DMU is compared with all other DMUs that produce during the same time period and where the role of time is ignored. However, this can be rather misleading since a dynamic context may give rise to seemingly excessive use of resources that are intended to produce beneficial results in future periods. As such, panel data prevail over cross-sectional data in that not only do they enable a DMU to be compared with other counterparts, but also because the movement of efficiency of a particular DMU can be tracked over a period of time. In so doing, panel data are more likely to reflect the real efficiency of a DMU. 
Initiated by Charnes, Clark, Cooper and Golany (1985), windows analysis is a timedependent version of DEA. The basic idea is to regard each DMU as if it were a different DMU in each of the reporting dates. Then each DMU is not necessarily compared with the whole data set, but instead only with alternative subsets of panel data. The windows analysis is based on the assumption that what was feasible in the past remains feasible forever, and that the treatment of time in windows analysis is more in the nature of an averaging over the periods of time covered by the window. It seems hard to find more than an ad hoc justification for the size of the window, as well as for the fact that part of the past is ignored (Tulkens and van den Eeckaut, 1995).

\section{Operationalisation}

\subsection{Data issues}

A thorough discussion of variable definition is provided in Song, Cullinane and Wang (2003), but can be summarised as follows. The input and output variables should reflect actual objectives and process of container port production as accurately as possible. As far as the former is concerned, the observed performance of a port might be closely related to its objective. For instance, a port is more likely to utilise state-of-the-art, expensive equipment to improve its productivity if its objective is simply to maximise cargo throughput. On the other hand, a port may be more willing to use cheaper equipment if its objective is simply to maximise profits.

The objectives of a port are a crucial consideration in defining the variables for efficiency measurement. For instance, if the objective of a port is to maximise its profits, then employment or any information on labour should be counted as an input variable. However, if the objective of a port is to increase employment, then information on labour should be accounted for as an output variable.

In this paper, the main port objective is assumed to be the minimisation of the use of input(s) and maximisation of the output(s). This objective is justified by the facts that, inter alia, i) contemporary container ports rely heavily upon sophisticated equipment and information technology (IT) rather than being labour-intensive; ii) in the light of the fierce and ever-increasing competition faced by each container port, to achieve this goal is more urgent than any other objective; and iii) this objective also conforms with the results of most existing research.

As container shipping lines are the most important clients of a container port, the transfer of cargo across a quay between ship and shore fundamentally decides the efficiency of a port, and is vital to its competitive position. In this production process (the quay transfer operation), the most important piece of equipment is the gantry crane. As a storage area, the container yard acts as a buffer between sea and inland transportation or transshipment. The size of a ship is very frequently thousands of times the size of the land vehicles that carry the cargo to and from the port. As such, the use of such storage space is normally inevitable. The main pieces of equipment used within a container yard are the yard gantry cranes and straddle carriers. Dowd and Leschine (1990) argue that the production of a container terminal depends on the efficient use of labour, land and equipment. The measurement of terminal production, therefore, is a means of quantifying efficiency in the utilisation of these three resources. Given the characteristics of container 
port production, the total quay length and the terminal area are the most suitable proxies for the 'land' factor input and the number of quay gantry cranes, the number of yard gantry cranes and the number of straddle carriers are the most suitable proxies for the 'equipment' factor input. Measures of these variables should be incorporated into the models as input variables.

In the light of the unavailability or unreliability of direct data, information on labour inputs is derived from a pre-determined relationship to terminal facilities. Notteboom, Coeck and van den Broeck (2000) point out that expert analysis has revealed that a fairly stable and close relationship exists between the number of gantry cranes and the number of staff in a container terminal. As such, labour information can be determined as a function of the facilities of a port. It should be emphasised, however, that there are a number of caveats that should be made explicit in making this assumption. For instance, with the rapid development of manufacturing technology, new products (such as driverless automated guided vehicles) need less labour in absolute numbers. Also, automatic stacking cranes have already been employed at some container ports. Thus, any pre-determined relationship between terminal facilities and the absolute number of stevedores employed is not a static one. At the same time, there does exist a difference in the use of labour in ports of different sizes or where different facilities are available or where different clients are served.

On the other hand, container throughput is unquestionably the most important and widely accepted indicator of port or terminal output. Almost all previous studies treat it as an output variable, because it closely relates to the need for cargo-related facilities and services and is the primary basis upon which container ports are compared, especially in assessing their relative size, investment magnitude or activity levels. Another consideration is that container throughput is the most appropriate and analytically tractable indicator of the effectiveness of the production of a port.

The sampling frame for the analysis was the world's leading container ports ranked in the top 30 in 2001. Although ranked in the top 30, five container ports (Shenzhen, Gioia Tauro, Tanjung Pelepas, Algeciras and San Juan) were finally excluded because either they have a shorter history than the study period or lack reliable data for analysis. Eight years of annual data from 1992 to 1999 are collected for each port. Thus, the sample for analysis comprised a total of 200 observations. The required secondary data are mainly taken from various issues of both the Containerisation International Yearbook and Lloyd's Ports of the World. The latest data available on port/terminal throughput was for 1999 and this was chosen as the basis for the analysis.

Based on the argument that container terminals are more suitable for one-to-one comparison than whole container ports (Wang, Song and Cullinane, 2002), this study initially intended to investigate individual container terminals. However, data sources often reported the required data, especially container throughput, at the aggregate level of the whole port, rather than on the basis of the individual terminals that may comprise each of those ports within the sample. In these cases, the input and output of a port are defined as the aggregation of the input and output of individual terminals within the port. It is important to recognise, however, that such aggregation may prove problematic in reflecting the true production efficiency of the individual terminals within the same port, particularly when these container terminals operate as independent units. Nevertheless, for a sample composed at the level of the port, the data used in the study is the most reliable and comprehensive available. 
A summary of the major characteristics of the finally selected input and output variables is presented in Table 1 .

\begin{tabular}{lllllll}
\hline & $\begin{array}{c}\text { Throughput } \\
\text { (TEU*) }\end{array}$ & $\begin{array}{c}\text { Quay } \\
\text { length } \\
(\mathbf{m})\end{array}$ & $\begin{array}{c}\text { Terminal } \\
\text { Area } \\
\text { (ha) }\end{array}$ & $\begin{array}{c}\text { Quayside } \\
\text { Gantry } \\
\text { (number) }\end{array}$ & $\begin{array}{c}\text { Yard } \\
\text { Gantry } \\
\text { (number) }\end{array}$ & $\begin{array}{c}\text { Straddle } \\
\text { Carrier } \\
\text { (number) }\end{array}$ \\
\hline \hline Max. & $15,944,793$ & 16,917 & 1,000 & 111 & 337 & 171 \\
Min. & 33,705 & 142 & 4 & 1 & 0 & 0 \\
Mean & $2,455,824$ & 4,609 & 194 & 29 & 39 & 31 \\
Standard Deviation & $2,459,148$ & 4,022 & 206 & 25 & 61 & 40 \\
\hline
\end{tabular}

Table 1: Descriptive statistics of the selected input and output variables

Note: * TEU is the abbreviation for "Twenty foot Equivalent Unit", referring to the most common standard size for a container of $20 \mathrm{ft}$ in length.

\subsection{Model orientation}

DEA models can be distinguished according to whether they are input- or output-oriented. The former is closely related to operational and managerial issues, whilst the latter is more related to planning and strategies. Both orientations have their usefulness in the container port industry context. As far as input-oriented models are concerned, the port industry is normally associated with long-life facilities and a long-term planning horizon and once the port is built, its output is roughly fixed within some range. A port is normally able to approximately predict its container throughput for the ensuing year at least. This is because a container port has a fairly stable customer base of shipping lines. Over the fairly short-term, container terminals should even be able to predict impending dramatic changes. A container terminal can also attempt to predict its future throughput by studying historic data or regional economic developments. In that case, how to efficiently use the inputs is the key to saving costs in port production.

On the other hand, with the rapid expansion of global business and international trade, many container ports must frequently review their capacity in order to ensure that they can provide satisfactory services to port users and maintain their competitive edge. Sometimes, the need to build a new terminal or increase capacity is inevitable. However, before a port implements such a plan, it is of great importance for the port to know whether it has fully used its existing facilities and that output has been maximised given the input. From this point of view, the output-oriented model provides a benchmark for the container industry.

Ultimately, it has been decided that output-oriented models should be chosen as the basis for the analysis undertaken herein. From a purely pragmatic point of view, the choice of an output-oriented approach greatly facilitates discussions for the case where there is a single output.

\section{$5 \quad$ Empirical results and analysis}

Without precise information on the returns to scale of the port production function and in order to facilitate the exploration of returns to scale, both DEA-CCR and DEA-BCC models are applied to derive the efficiency of the container ports under study. The software DEA-Solver-PRO 3.0 (Cooper et al, 2000) is employed to derive a solution to the model. 
Table 2

\begin{tabular}{|c|c|c|c|c|c|c|c|c|c|c|}
\hline \multirow[b]{2}{*}{ Port } & \multicolumn{8}{|c|}{ Efficiency Scores } & \multicolumn{2}{|c|}{ Summary Measures } \\
\hline & 1992 & 1993 & 1994 & 1995 & 1996 & 1997 & 1998 & 1999 & Mean & S.D. \\
\hline Hong & 72.11 & 71.7 & 76.57 & & & & & & 89.10 & 10.69 \\
\hline \multirow[t]{5}{*}{ Kong } & & 71.7 & 76.57 & 100 & & & & & & \\
\hline & & & 94.25 & 97.02 & 100 & & & & & \\
\hline & & & & 89.35 & 93.87 & 100 & & & & \\
\hline & & & & & & 100 & 100 & & & \\
\hline & & & & & & 87.11 & 88.85 & 93.07 & & \\
\hline \multirow[t]{6}{*}{ Singapore } & 94.97 & 100 & 68.84 & & & & & & 88.73 & 11.54 \\
\hline & & 100 & 68.23 & 70.87 & & & & & & \\
\hline & & & 80.34 & 83.44 & 100 & & & & & \\
\hline & & & & 76.41 & 91.57 & 100 & & & & \\
\hline & & & & & 85.52 & 93.39 & 100 & & & \\
\hline & & & & & & 88.65 & 94.92 & 100 & & \\
\hline \multirow[t]{6}{*}{ Busan } & 78.56 & 91.83 & 100 & & & & & & 78.73 & 16.63 \\
\hline & & 86.27 & 98.96 & 90.61 & & & & & & \\
\hline & & & 88.97 & 88.48 & 100 & & & & & \\
\hline & & & & 71.01 & 79.38 & 75.38 & & & & \\
\hline & & & & & 79.23 & 74.33 & 52.21 & & & \\
\hline & & & & & & 65.13 & 49.37 & 47.51 & & \\
\hline \multirow[t]{6}{*}{ Kaohsiung } & 100 & 94.01 & 100 & & & & & & 94.79 & 5.21 \\
\hline & & 88.61 & 93.65 & 100 & & & & & & \\
\hline & & & 93.65 & 100 & 96.69 & & & & & \\
\hline & & & & 97.26 & 92.94 & 97.06 & & & & \\
\hline & & & & & 90.24 & 90.79 & 100 & & & \\
\hline & & & & & & 81.5 & 89.77 & 100 & & \\
\hline \multirow{6}{*}{ Shanghai } & 75.13 & 94.28 & 100 & & & & & & 83.26 & 12.54 \\
\hline & & 86.98 & 95.77 & 93.52 & & & & & & \\
\hline & & & 86.81 & 78.19 & 80.56 & & & & & \\
\hline & & & & 65.77 & 70.84 & 86.63 & & & & \\
\hline & & & & & 69.25 & 82.19 & 100 & & & \\
\hline & & & & & & 59.86 & 72.83 & 100 & & \\
\hline \multirow[t]{6}{*}{ Rotterdam } & 39.1 & 38.92 & 41.72 & & & & & & 50.69 & 9.89 \\
\hline & & 36.92 & 40.1 & 47.64 & & & & & & \\
\hline & & & 40.1 & 47.64 & 65.26 & & & & & \\
\hline & & & & 46.19 & 63.71 & 57.19 & & & & \\
\hline & & & & & 61.47 & 55.39 & 64.36 & & & \\
\hline & & & & & & 51.21 & 59.45 & 56.05 & & \\
\hline \multirow{6}{*}{$\begin{array}{l}\text { Los } \\
\text { Angeles }\end{array}$} & 98.02 & 95.64 & 100 & & & & & & 98.22 & 3.09 \\
\hline & & 94.51 & 98.62 & 100 & & & & & & \\
\hline & & & 98.61 & 100 & 100 & & & & & \\
\hline & & & & 100 & 100 & 100 & & & & \\
\hline & & & & & 100 & 100 & 94.95 & & & \\
\hline & & & & & & 100 & 88.29 & 99.28 & & \\
\hline \multirow[t]{6}{*}{ Hamburg } & 47.04 & 49.24 & 55.09 & & & & & & 53.96 & 4.85 \\
\hline & & 46.22 & 51.7 & 52.73 & & & & & & \\
\hline & & & 51.7 & 52.73 & 55.55 & & & & & \\
\hline & & & & 51.33 & 53.43 & 57.53 & & & & \\
\hline & & & & & 51.95 & 55.97 & 65.51 & & & \\
\hline & & & & & & 52.65 & 62.04 & 58.92 & & \\
\hline Long & 60.57 & 55.85 & 67.65 & & & & & & 68.29 & 14.86 \\
\hline \multirow[t]{5}{*}{ Beach } & & 54.69 & 67.33 & 74.78 & & & & & & \\
\hline & & & 63.01 & 71.05 & 69.71 & & & & & \\
\hline & & & & 58.47 & 56.54 & 65.89 & & & & \\
\hline & & & & & 52.99 & 59.94 & 100 & & & \\
\hline & & & & & & 57.85 & 92.95 & 100 & & \\
\hline
\end{tabular}


Table 2 (Continued)

\begin{tabular}{|c|c|c|c|c|c|c|c|c|c|c|}
\hline \multirow[b]{2}{*}{ Port } & \multicolumn{8}{|c|}{ Efficiency Scores } & \multicolumn{2}{|c|}{ Summary Measures } \\
\hline & 1992 & 1993 & 1994 & 1995 & 1996 & 1997 & 1998 & 1999 & Mean & S.D. \\
\hline \multirow[t]{6}{*}{ Antwerp } & 34.48 & 35.24 & 40.82 & & & & & & 33.47 & 5.00 \\
\hline & & 32.37 & 37.43 & 38.67 & & & & & & \\
\hline & & & 37.43 & 38.67 & 41.79 & & & & & \\
\hline & & & & 26.14 & 29.49 & 28.85 & & & & \\
\hline & & & & & 28.88 & 28.04 & 30.62 & & & \\
\hline & & & & & & 27.25 & 29.83 & 36.42 & & \\
\hline \multirow[t]{6}{*}{ Port Klang } & 100 & 64.35 & 78.69 & & & & & & 55.96 & 20.95 \\
\hline & & 60.52 & & 75.78 & & & & & & \\
\hline & & & 74 & 75.78 & 40.55 & & & & & \\
\hline & & & & 69.23 & 34.34 & 40.97 & & & & \\
\hline & & & & & 33.36 & 39.31 & 39.57 & & & \\
\hline & & & & & & 32.64 & 31.76 & 42.34 & & \\
\hline \multirow[t]{6}{*}{ Dubai } & 85.23 & 89.21 & 100 & & & & & & 68.21 & 17.23 \\
\hline & & 83.41 & 93.49 & 49.91 & & & & & & \\
\hline & & & 93.49 & 54.16 & 67.34 & & & & & \\
\hline & & & & 49.44 & 57.82 & 58.67 & & & & \\
\hline & & & & & 55.93 & 57.66 & 62.19 & & & \\
\hline & & & & & & 54.37 & 58.63 & 56.82 & & \\
\hline \multirow{6}{*}{$\begin{array}{l}\text { New York/ } \\
\text { New Jersey }\end{array}$} & 57.17 & 49.74 & 67.95 & & & & & & 76.34 & 18.27 \\
\hline & & 46.43 & 63.06 & 100 & & & & & & \\
\hline & & & 63.06 & 100 & 97.86 & & & & & \\
\hline & & & & 90.3 & 83.27 & 97.71 & & & & \\
\hline & & & & & 79.11 & 92.82 & 60.24 & & & \\
\hline & & & & & & 89.86 & 59.76 & 75.71 & & \\
\hline Bremen/ & 81.58 & 85.39 & 98.96 & & & & & & 80.34 & 7.86 \\
\hline \multirow[t]{5}{*}{ Bremerhaven } & & 71.77 & 83.18 & 84.54 & & & & & & \\
\hline & & & 83.18 & 84.54 & 85.48 & & & & & \\
\hline & & & & 70.39 & 74.11 & 72.78 & & & & \\
\hline & & & & & 74.45 & 73.06 & 77.75 & & & \\
\hline & & & & & & 73.23 & 77.93 & 93.78 & & \\
\hline \multirow[t]{6}{*}{ Felixstowe } & 69.61 & 73.95 & 78.27 & & & & & & 60.39 & 9.21 \\
\hline & & 63.6 & 67.33 & 72.02 & & & & & & \\
\hline & & & 57.69 & 59.44 & 63.95 & & & & & \\
\hline & & & & 50.02 & 53.82 & 57.68 & & & & \\
\hline & & & & & 52.37 & 55.84 & 63.13 & & & \\
\hline & & & & & & 44.95 & 51.86 & 51.56 & & \\
\hline \multirow[t]{6}{*}{ Manila } & 71.11 & 54.36 & 60.11 & & & & & & 58.07 & 11.45 \\
\hline & & 54.05 & 58.02 & 79.31 & & & & & & \\
\hline & & & 50.24 & 69.45 & 81.14 & & & & & \\
\hline & & & & 54.62 & 63.81 & 51.48 & & & & \\
\hline & & & & & 63.79 & 51.48 & 42.33 & & & \\
\hline & & & & & & 51.1 & 41.58 & 47.28 & & \\
\hline \multirow[t]{6}{*}{ Tokyo } & 49.59 & 43.4 & 48.26 & & & & & & 51.90 & 6.49 \\
\hline & & 40.13 & 45.19 & 53.19 & & & & & & \\
\hline & & & 48.14 & 57.52 & 61.97 & & & & & \\
\hline & & & & 53.54 & 55.99 & 53.88 & & & & \\
\hline & & & & & 55.17 & 52.23 & 57.36 & & & \\
\hline & & & & & & 44.82 & 48.9 & 64.91 & & \\
\hline \multirow[t]{6}{*}{ Qingdao } & 67.82 & 54.15 & 88.07 & & & & & & 77.15 & 18.09 \\
\hline & & 50.58 & 82.27 & 100 & & & & & & \\
\hline & & & 53.09 & 74.07 & 100 & & & & & \\
\hline & & & & 58.25 & 78.64 & 100 & & & & \\
\hline & & & & & 78.64 & 100 & 78.04 & & & \\
\hline & & & & & & 100 & 55.12 & 69.93 & & \\
\hline
\end{tabular}


Table 2 (Continued)

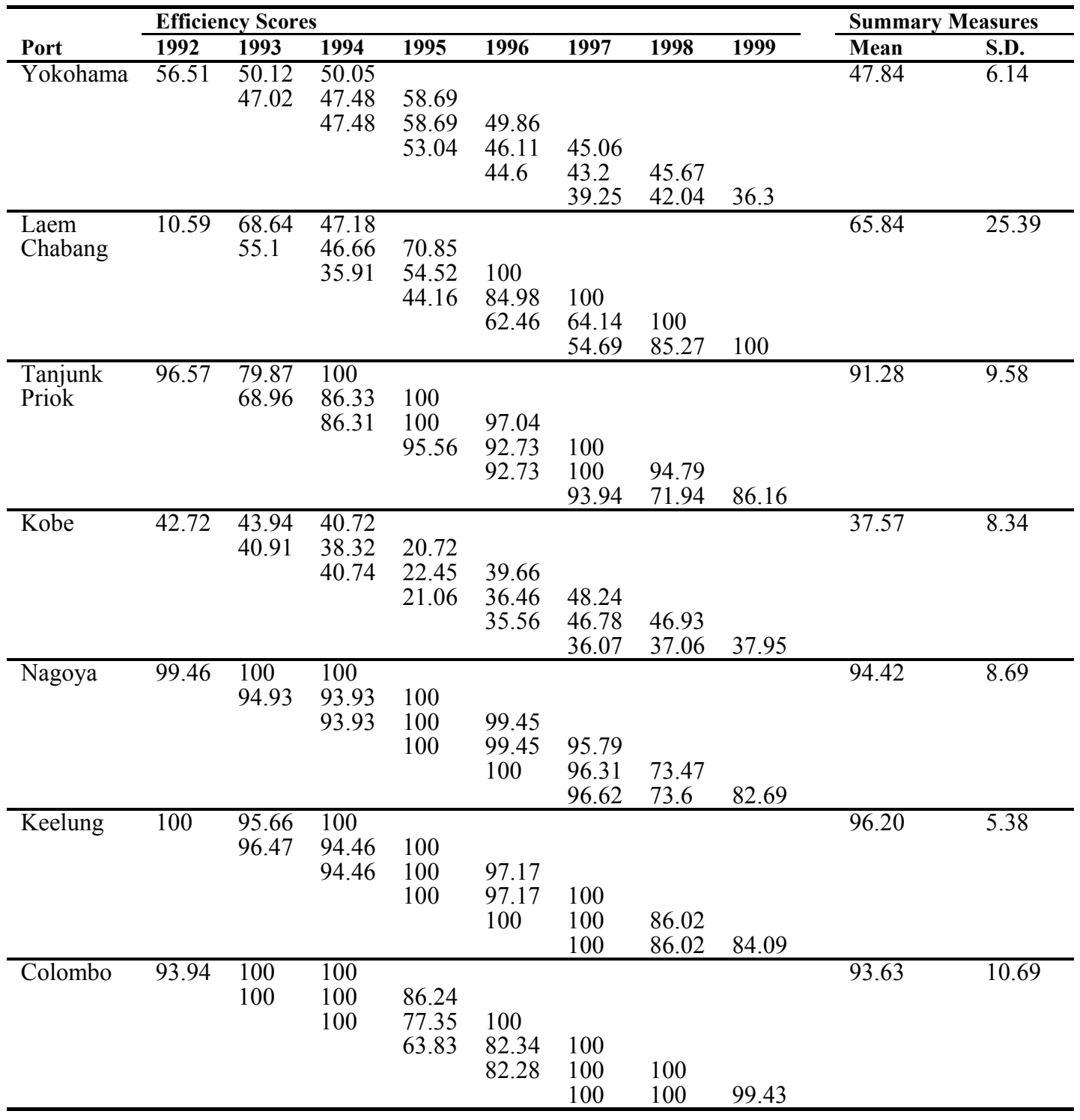

Table 2 DEA-CCR windows analysis for container port efficiency $(100=$ 'efficient') 
Table 3

\begin{tabular}{|c|c|c|c|c|c|c|c|c|c|c|}
\hline \multirow[b]{2}{*}{ Port } & \multicolumn{8}{|c|}{ Efficiency Scores } & \multicolumn{2}{|c|}{ Summary Measures } \\
\hline & 1992 & 1993 & 1994 & 1995 & 1996 & 1997 & 1998 & 1999 & Mean & S.D. \\
\hline \multirow{6}{*}{$\begin{array}{l}\text { Hong } \\
\text { Kong }\end{array}$} & 72.45 & 71.85 & 76.6 & & & & & & 91.40 & 11.51 \\
\hline & & 71.82 & 76.59 & 100 & & & & & & \\
\hline & & & 94.29 & 98.71 & 100 & & & & & \\
\hline & & & & 92.19 & 97.07 & 100 & & & & \\
\hline & & & & & 93.54 & 100 & 100 & & & \\
\hline & & & & & & 100 & 100 & 100 & & \\
\hline \multirow[t]{6}{*}{ Singapore } & 95.38 & 100 & 100 & & & & & & 93.66 & 7.70 \\
\hline & & 100 & 96.29 & 100 & & & & & & \\
\hline & & & 80.34 & 83.44 & 100 & & & & & \\
\hline & & & & 76.41 & 91.57 & 100 & & & & \\
\hline & & & & & 85.52 & 93.39 & 100 & & & \\
\hline & & & & & & 88.65 & 94.92 & 100 & & \\
\hline \multirow[t]{6}{*}{ Busan } & 80.75 & 94.39 & 100 & & & & & & 86.59 & 16.01 \\
\hline & & 88.91 & 100 & 96.64 & & & & & & \\
\hline & & & 88.97 & 93.08 & 100 & & & & & \\
\hline & & & & 93.08 & 100 & 93.32 & & & & \\
\hline & & & & & 100 & 90.94 & 61.11 & & & \\
\hline & & & & & & 70.56 & 52.59 & 54.35 & & \\
\hline \multirow[t]{6}{*}{ Kaohsiung } & 100 & 94.61 & 100 & & & & & & 95.59 & 5.27 \\
\hline & & 88.61 & 93.65 & 100 & & & & & & \\
\hline & & & 93.65 & 100 & 96.76 & & & & & \\
\hline & & & & 100 & 96.7 & 100 & & & & \\
\hline & & & & & 94.55 & 90.79 & 100 & & & \\
\hline & & & & & & 81.5 & 89.77 & 100 & & \\
\hline \multirow[t]{6}{*}{ Shanghai } & 76.43 & 95.91 & 100 & & & & & & 86.23 & 11.51 \\
\hline & & 87.19 & 96.05 & 95.4 & & & & & & \\
\hline & & & 87.41 & 85.22 & 92.33 & & & & & \\
\hline & & & & 75.85 & 80.49 & 92.81 & & & & \\
\hline & & & & & 72.24 & 82.19 & 100 & & & \\
\hline & & & & & & 59.86 & 72.83 & 100 & & \\
\hline \multirow[t]{6}{*}{ Rotterdam } & 82.46 & 82.05 & 87.75 & & & & & & 84.72 & 5.61 \\
\hline & & 77.21 & 82.79 & 90.94 & & & & & & \\
\hline & & & 83.5 & 91.05 & 95.02 & & & & & \\
\hline & & & & 84.08 & 88.05 & 94.63 & & & & \\
\hline & & & & & 80.11 & 85.99 & 84.64 & & & \\
\hline & & & & & & 77.33 & 76.82 & 80.45 & & \\
\hline \multirow{6}{*}{$\begin{array}{l}\text { Los } \\
\text { Angeles }\end{array}$} & 100 & 99 & 100 & & & & & & 98.75 & 2.74 \\
\hline & & 96.9 & 98.62 & 100 & & & & & & \\
\hline & & & 98.62 & 100 & 100 & & & & & \\
\hline & & & & 100 & 100 & 100 & & & & \\
\hline & & & & & 100 & 100 & 95.32 & & & \\
\hline & & & & & & 100 & 89.06 & 99.97 & & \\
\hline \multirow[t]{6}{*}{ Hamburg } & 75.49 & 80.41 & 81.3 & $\mathrm{x}$ & & & & & 73.19 & 5.96 \\
\hline & & 75.15 & 76.04 & 80.65 & & & & & & \\
\hline & & & 66.22 & 70.63 & 74.85 & & & & & \\
\hline & & & & 63.71 & 67.57 & 74.14 & & & & \\
\hline & & & & & 63.93 & 70.11 & 81.36 & & & \\
\hline & & & & & & 65.7 & 77.09 & 73.1 & & \\
\hline Long & 80.08 & 83.49 & 100 & & & & & & 85.36 & 10.15 \\
\hline \multirow[t]{5}{*}{ Beach } & & 64.79 & 80.19 & 88.59 & & & & & & \\
\hline & & & 79.71 & 88.06 & 88.74 & & & & & \\
\hline & & & & 83.61 & 83.85 & 97.54 & & & & \\
\hline & & & & & 72.44 & 79.42 & 100 & & & \\
\hline & & & & & & 73.04 & 92.95 & 100 & & \\
\hline
\end{tabular}


Table 3 (Continued)

\begin{tabular}{|c|c|c|c|c|c|c|c|c|c|c|}
\hline \multirow[b]{2}{*}{ Port } & \multicolumn{8}{|c|}{ Efficiency Scores } & \multicolumn{2}{|c|}{ Summary Measures } \\
\hline & 1992 & 1993 & 1994 & 1995 & 1996 & 1997 & 1998 & 1999 & Mean & S.D. \\
\hline \multirow[t]{6}{*}{ Antwerp } & 76.58 & 78.27 & 92.12 & & & & & & 71.17 & 10.43 \\
\hline & & 72.72 & 85.59 & 90.28 & & & & & & \\
\hline & & & 61.34 & 64.58 & 72.15 & & & & & \\
\hline & & & & 55.87 & 62.15 & 65.88 & & & & \\
\hline & & & & & & 63.89 & 71.27 & & & \\
\hline & & & & & & 61.6 & 68.99 & 76.35 & & \\
\hline \multirow[t]{6}{*}{ Port Klang } & 100 & 70.6 & 86.33 & & & & & & 60.51 & 23.47 \\
\hline & & 74.76 & 91.42 & 89.28 & & & & & & \\
\hline & & & 79.17 & 77.57 & 41.23 & & & & & \\
\hline & & & & 69.78 & 38.41 & 42.27 & & & & \\
\hline & & & & & & 39.56 & 39.74 & & & \\
\hline & & & & & & 33.62 & 33.79 & 45.96 & & \\
\hline \multirow[t]{6}{*}{ Dubai } & 88.7 & 89.21 & 100 & & & & & & 71.59 & 17.39 \\
\hline & & 89.21 & 100 & 50.58 & & & & & & \\
\hline & & & 95.98 & 54.19 & 67.63 & & & & & \\
\hline & & & & 52.08 & 61.46 & 70.86 & & & & \\
\hline & & & & & 56.91 & 65.53 & 70.67 & & & \\
\hline & & & & & & 57.02 & 61.49 & 57.11 & & \\
\hline \multirow{6}{*}{$\begin{array}{l}\text { New York/ } \\
\text { New Jersey }\end{array}$} & 90.58 & 85.39 & 95.2 & & & & & & 92.24 & 9.40 \\
\hline & & 79.27 & 88.21 & 100 & & & & & & \\
\hline & & & 66.4 & 100 & 100 & & & & & \\
\hline & & & & 94.85 & 85.23 & 100 & & & & \\
\hline & & & & & 85.23 & 100 & 100 & & & \\
\hline & & & & & & 100 & 89.93 & 100 & & \\
\hline \multirow{6}{*}{$\begin{array}{l}\text { Bremen/ } \\
\text { Bremerhaven }\end{array}$} & 87.12 & 90.21 & 100 & & & & & & 89.90 & 8.74 \\
\hline & & 88.76 & 98.39 & 100 & & & & & & \\
\hline & & & 97.31 & 98.9 & 100 & & & & & \\
\hline & & & & 77.05 & 77.9 & 85.97 & & & & \\
\hline & & & & & 77.9 & 85.97 & 91.48 & & & \\
\hline & & & & & & 78.1 & 83.1 & 100 & & \\
\hline \multirow[t]{6}{*}{ Felixstowe } & 88.93 & 94.47 & 100 & & & & & & 70.95 & 13.04 \\
\hline & & 66.3 & 70.18 & 77.14 & & & & & & \\
\hline & & & 64.15 & 70.63 & 75.05 & & & & & \\
\hline & & & & 63.35 & 68.17 & 73.25 & & & & \\
\hline & & & & & 61.08 & 66.77 & 74.07 & & & \\
\hline & & & & & & 49.63 & 55.6 & 58.34 & & \\
\hline \multirow[t]{6}{*}{ Manila } & 81.9 & 57.33 & 61.75 & & & & & & 67.03 & 13.45 \\
\hline & & 55.71 & 59.44 & 82.11 & & & & & & \\
\hline & & & 53.94 & 70.56 & 82.43 & & & & & \\
\hline & & & & 68.66 & 80.21 & 87.83 & & & & \\
\hline & & & & & 79.43 & 77.79 & 58.06 & & & \\
\hline & & & & & & 54.14 & 44.34 & 50.99 & & \\
\hline \multirow[t]{6}{*}{ Tokyo } & 50.48 & 43.95 & 48.75 & & & & & & 52.68 & 6.50 \\
\hline & & 40.6 & 45.64 & 53.81 & & & & & & \\
\hline & & & 48.2 & 57.61 & 61.99 & & & & & \\
\hline & & & & 55.98 & 58.94 & 55.81 & & & & \\
\hline & & & & & 55.29 & 52.37 & 57.55 & & & \\
\hline & & & & & & 46.88 & 49.11 & 65.19 & & \\
\hline \multirow{6}{*}{ Qingdao } & 100 & 61.48 & 100 & & & & & & 83.26 & 17.35 \\
\hline & & 61.48 & 100 & 100 & & & & & & \\
\hline & & & 53.09 & 74.07 & 100 & & & & & \\
\hline & & & & 58.25 & 78.64 & 100 & & & & \\
\hline & & & & & 78.64 & 100 & 78.07 & & & \\
\hline & & & & & & 100 & 68.3 & 86.64 & & \\
\hline
\end{tabular}


Table 3 (Continued)

\begin{tabular}{|c|c|c|c|c|c|c|c|c|c|c|}
\hline \multirow[b]{2}{*}{ Port } & \multicolumn{8}{|c|}{ Efficiency Scores } & \multicolumn{2}{|c|}{ Summary Measures } \\
\hline & 1992 & 1993 & 1994 & 1995 & 1996 & 1997 & 1998 & 1999 & Mean & S.D. \\
\hline \multirow{6}{*}{ Yokohama } & 59.47 & 52.55 & 54.96 & & & & & & 50.25 & 6.75 \\
\hline & & 49.28 & 51.57 & 61.38 & & & & & & \\
\hline & & & 50.68 & 60.91 & 51.83 & & & & & \\
\hline & & & & 56.72 & 48.58 & 48.24 & & & & \\
\hline & & & & & 44.63 & 44.26 & 47.63 & & & \\
\hline & & & & & & 40.15 & 43.72 & 37.93 & & \\
\hline \multirow{6}{*}{$\begin{array}{l}\text { Laem } \\
\text { Chabang }\end{array}$} & 15.42 & 100 & 48.97 & & & & & & 74.36 & 27.67 \\
\hline & & 100 & 51.68 & 78.46 & & & & & & \\
\hline & & & 37.24 & 56.55 & 100 & & & & & \\
\hline & & & & 46.13 & 100 & 100 & & & & \\
\hline & & & & & 100 & 64.14 & 100 & & & \\
\hline & & & & & & 54.69 & 85.27 & 100 & & \\
\hline \multirow{6}{*}{$\begin{array}{l}\text { Tanjunk } \\
\text { Priok }\end{array}$} & 100 & 79.87 & 100 & & & & & & 92.00 & 9.75 \\
\hline & & 68.96 & 86.34 & 100 & & & & & & \\
\hline & & & 86.32 & 100 & 97.04 & & & & & \\
\hline & & & & 95.56 & 92.73 & 100 & & & & \\
\hline & & & & & 92.73 & 100 & 95.58 & & & \\
\hline & & & & & & 100 & 73.2 & 87.67 & & \\
\hline \multirow[t]{6}{*}{ Kobe } & 51.78 & 50.76 & 49.47 & & & & & & 43.47 & 10.60 \\
\hline & & 48.06 & 47.44 & 23.89 & & & & & & \\
\hline & & & 48.78 & 25.68 & 41.39 & & & & & \\
\hline & & & & 23.75 & 38.81 & 62.65 & & & & \\
\hline & & & & & 35.57 & 51.75 & 51.66 & & & \\
\hline & & & & & & 41.73 & 43.96 & 45.33 & & \\
\hline \multirow[t]{6}{*}{ Nagoya } & 99.98 & 100 & 100 & & & & & & 95.64 & 8.96 \\
\hline & & 100 & 100 & 100 & & & & & & \\
\hline & & & 100 & 100 & 99.45 & & & & & \\
\hline & & & & 100 & 99.45 & 95.95 & & & & \\
\hline & & & & & 100 & 96.37 & 73.6 & & & \\
\hline & & & & & & 100 & 73.6 & 83.15 & & \\
\hline \multirow[t]{6}{*}{ Keelung } & 100 & 95.66 & 100 & & & & & & 96.39 & 5.46 \\
\hline & & 100 & 94.46 & 100 & & & & & & \\
\hline & & & 94.46 & 100 & 97.17 & & & & & \\
\hline & & & & 100 & 97.17 & 100 & & & & \\
\hline & & & & & 100 & 100 & 86.02 & & & \\
\hline & & & & & & 100 & 86.02 & 84.09 & & \\
\hline \multirow[t]{6}{*}{ Colombo } & 100 & 100 & 100 & & & & & & 98.84 & 4.79 \\
\hline & & 100 & 100 & 100 & & & & & & \\
\hline & & & 100 & 79.65 & 100 & & & & & \\
\hline & & & & 100 & 100 & 100 & & & & \\
\hline & & & & & 100 & 100 & 100 & & & \\
\hline & & & & & & 100 & 100 & 99.43 & & \\
\hline
\end{tabular}

Table 3 DEA-BCC windows analysis for container port efficiency $(100=$ 'efficient' $)$

Tables 2 and 3 report the results for the DEA windows analysis, with each container port represented as if it were a different DMU at each of the three successive dates noted at the top of each column. As previously mentioned, no theory underpins the definition of window size. As such, the length of the window used herein is defined as three. Although seemingly rather an arbitrary choice, this does accord with the original work in Charnes, Clark, Cooper and Golany (1985). Six separate windows are represented as separate rows in Tables 2 and 3. Taking Hong Kong as an example, in Table 2 the efficiency of Hong Kong container port in the first window is 72.11, 71.70 and 76.57. These figures correspond to the estimated relative efficiency of Hong Kong container port for 1992, 1993 and 1994. In the third window, relative efficiency estimates of $94.25,97.02$ and 100 
correspond respectively to 1994,1995 and 1996 . The same interpretive process can be applied to Tables 3 and 4. The average of the 18 DEA efficiency scores and associated standard deviations are presented in the columns denoted "Mean" and "S.D".

The approach used in formulating Tables 2 and 3 lends itself to a study of 'trends' and the examination of the 'stability' of efficiency across, as well as within, windows by the adoption of 'row views' and 'column views' respectively. For instance, a cursory glance at Table 3 may provoke the conclusion that the efficiency of a container terminal differs significantly over time. Still taking Hong Kong as an example, its efficiency varies from 72.45 in year 1992 to 100 during 1997 through 1999 (adopting a 'row view' perspective). At the same time, the efficiency of a DMU within the different windows can also vary substantially (adopting a 'column view' perspective). This variation reflects simultaneously both the absolute performance of a port over time and the relative performance of that port in comparison to the others in the sample.

The relationship between the mean efficiency scores and their standard deviations is shown in Figure 2, where a low correlation between mean efficiency scores and their standard deviations can be seen (the correlation coefficient is -0.02 and -0.30 , respectively corresponding to DEA-CCR and DEA-BCC windows analysis). A two-tailed test of significance reveals that these correlation coefficients are statistically insignificant at the $5 \%$ level $(\mathrm{t}=-0.1195, \mathrm{p}=0.4530$ under the DEA-CCR specification and $\mathrm{t}=-1.531, \mathrm{p}=$ 0.0697 under the DEA-BCC specification, with 23 degrees of freedom). In a practical sense, this implies that the efficiency of all the ports (whether or not they are more or less efficient on average) exhibits a similar level of fluctuation over time. This finding differs from the empirical results of Charnes, Clark, Cooper and Golany (1985) who found that, for the maintenance units in the U.S. Air Force, a low mean efficiency tended to be accompanied by high variance.

The relationship between efficiency and scale of production can be relatively simply inferred from an examination of the mean efficiency scores and container throughput at ports over time, as depicted in Figure 3. Since the correlation coefficients of the mean efficiency scores against container throughput are respectively only 0.19 and 0.26 and a two-tailed $t$ test reveals that these are not statistically significant at the $5 \%$ level $(\mathrm{t}=0.928$, $\mathrm{p}=0.1815$ under the DEA-CCR specification and $\mathrm{t}=1.291, \mathrm{p}=0.1047$ under the DEABCC specification, with 23 degrees of freedom), it would appear that the efficiency of a port is not significantly influenced by its size.

In order to further study the scale properties of container port production, scale efficiency, as introduced in equation (7), and the sum of weights e $\lambda^{\prime}$ under the specification of the CCR model are inspected. Table 4 details the scale properties of each container port at different times and over different windows. Most ports $(65.33 \%)$ exhibit constant returns to scale, compared with $23.56 \%$ and $11.11 \%$ of the ports that exhibit decreasing and increasing returns to scale, respectively. This indicates that production scale is not the main source of inefficiency for most container ports although, as expected, many small ports exhibit increasing returns to scale, while large ports appear to exhibit decreasing returns to scale. 

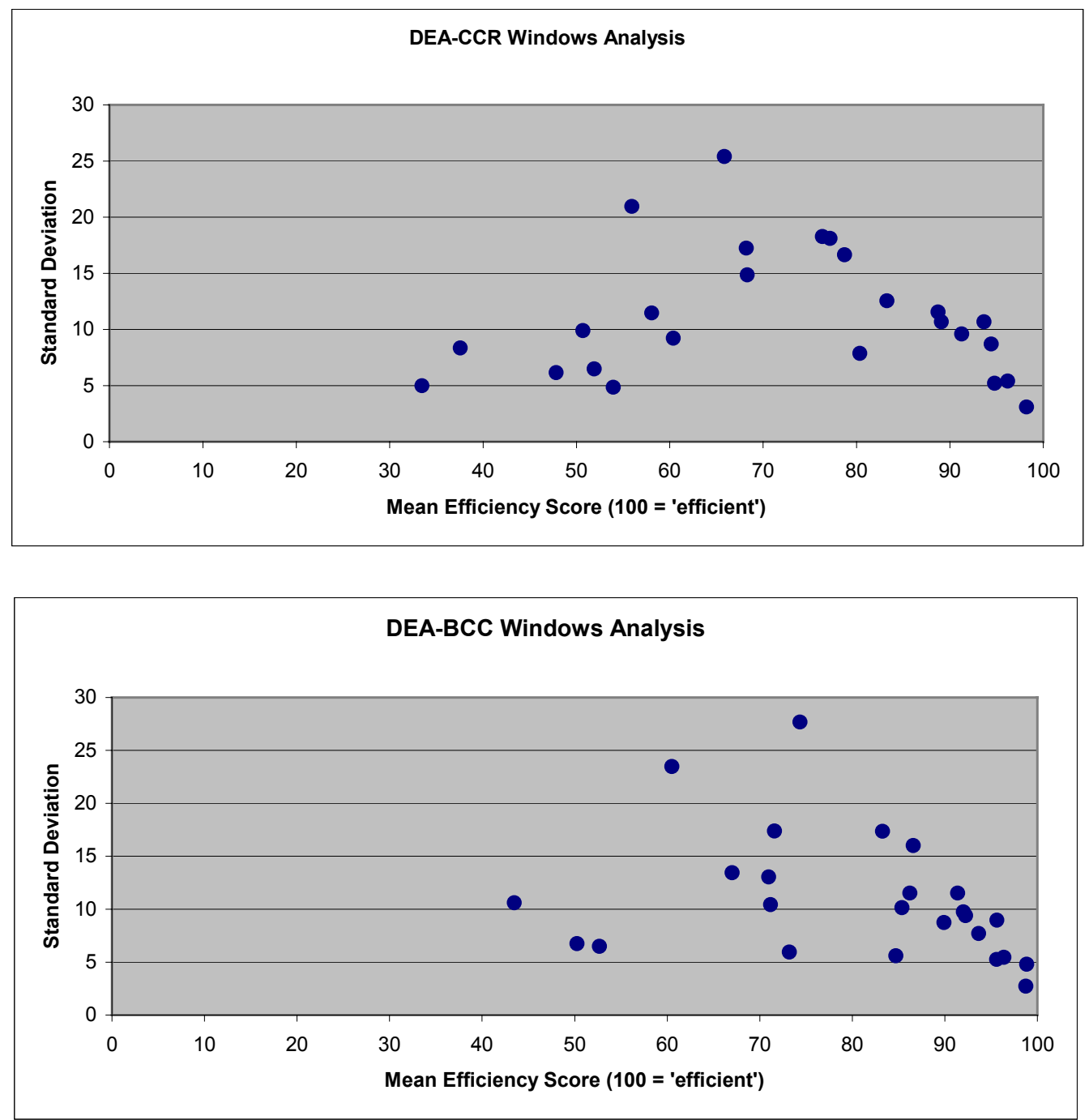

Figure 2: Relationship between efficiency and standard deviation 

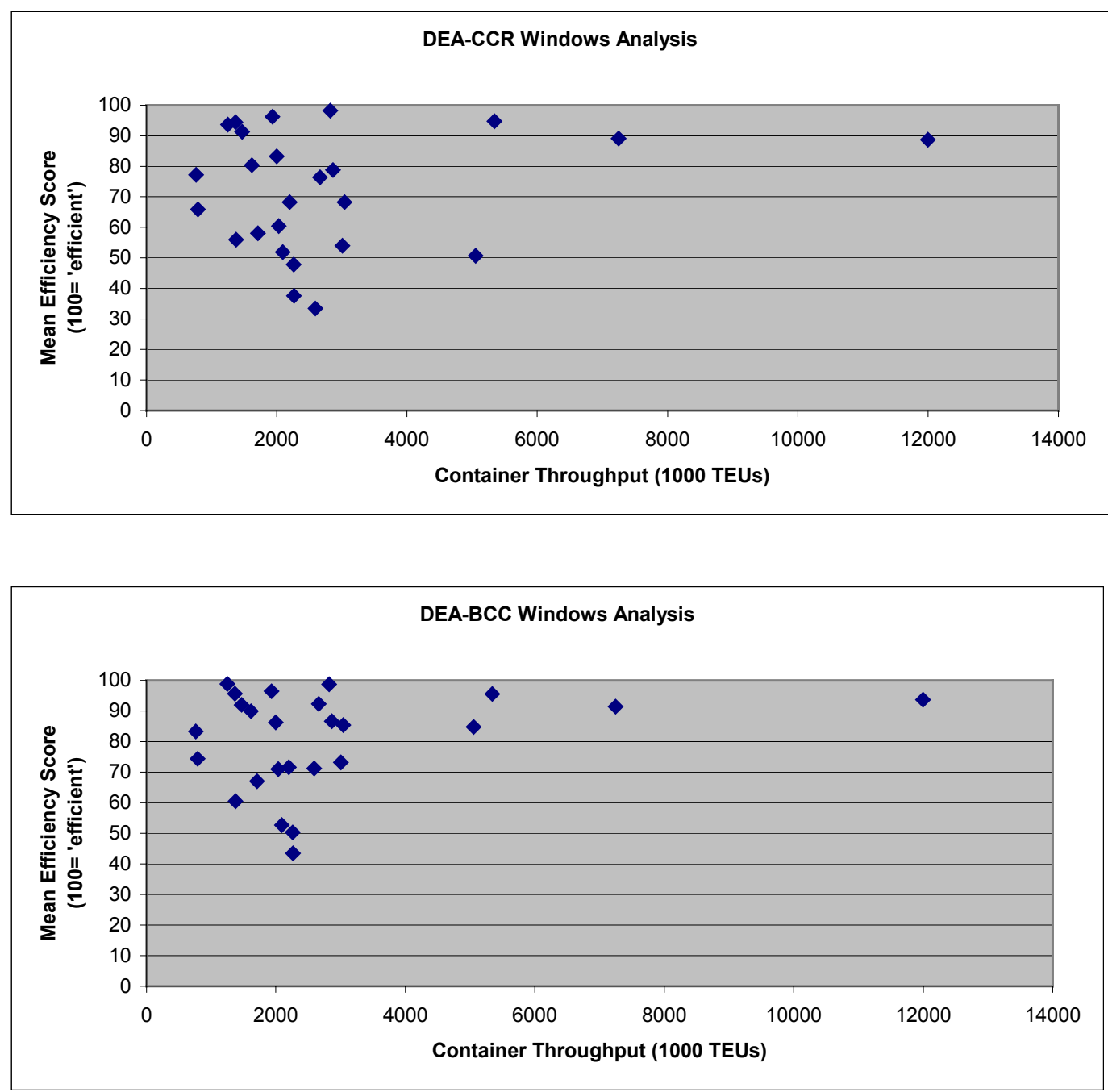

Figure 3: Relationship between efficiency and production scale 
Table 4

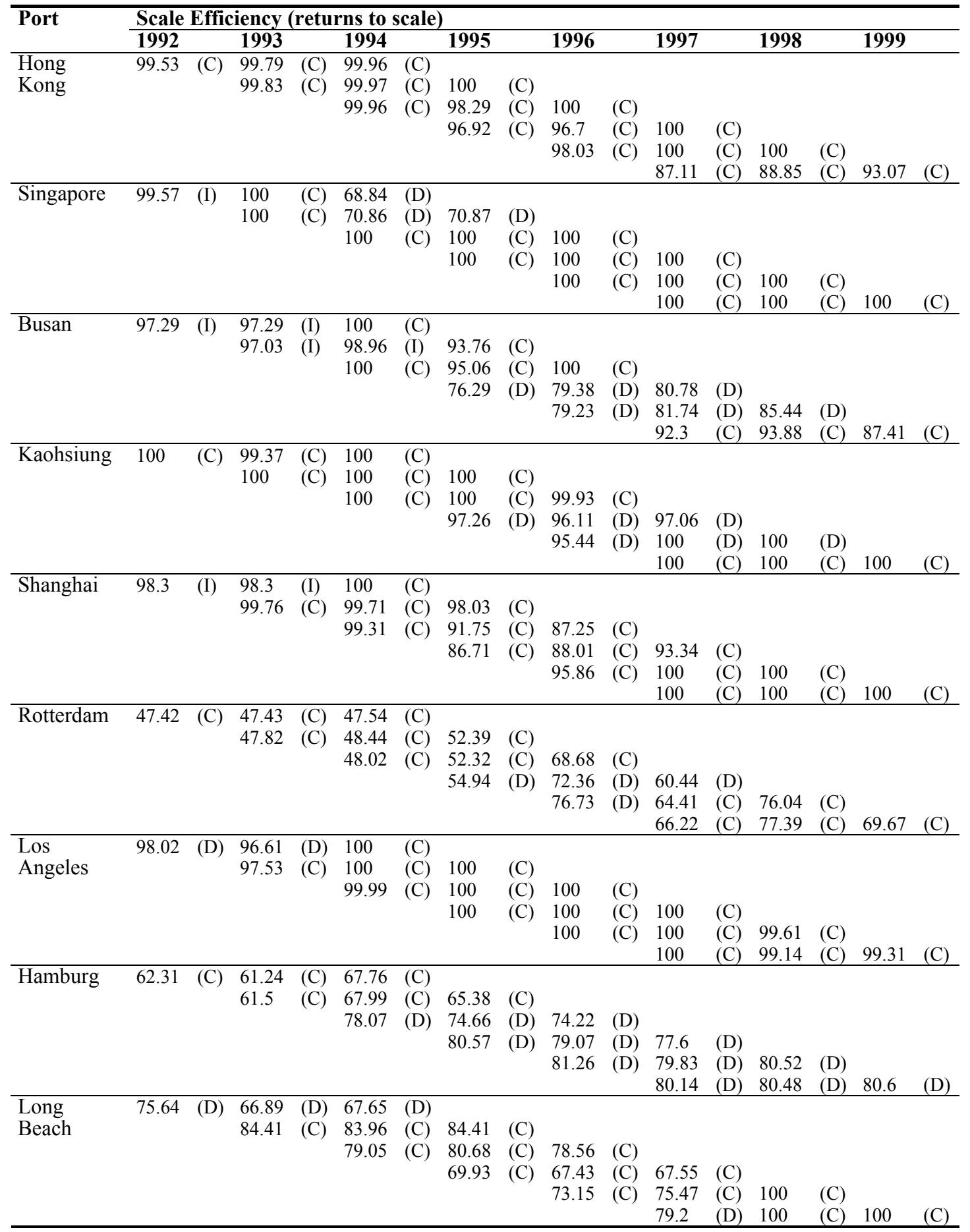




\section{Table 4 (Continued)}

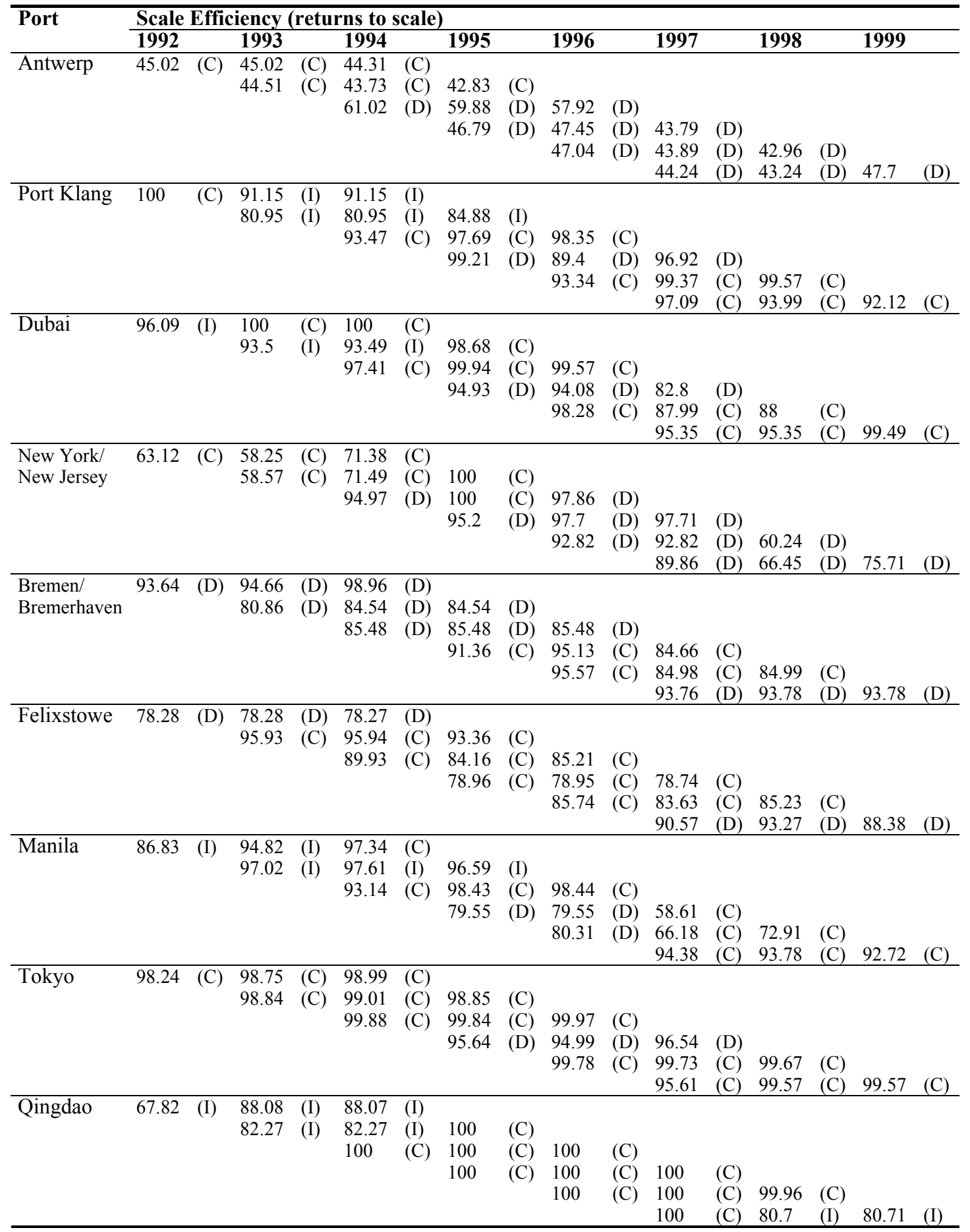


Table 4 (Continued)

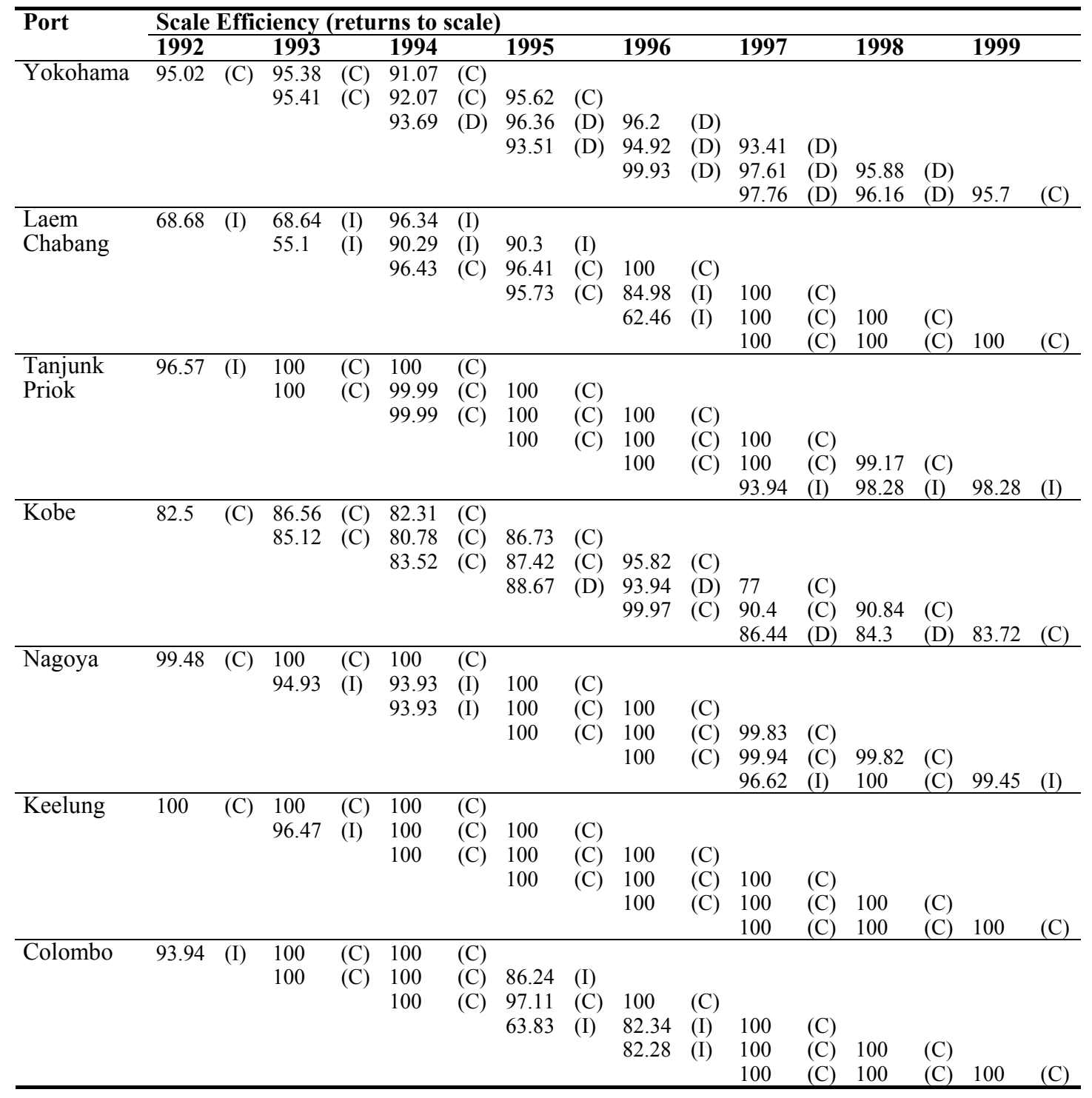

Table 4 Scale properties of container port production $(100=$ 'efficient')

Note: (C) indicates Constant returns to scale [where a proportional change in input(s) results in the same proportional change in output(s)]; (I) indicates Increasing returns to scale [where a proportional change in input(s) results in a more than proportional change in output(s)]; (D)indicates Decreasing returns to scale [where a proportional change in input(s) results in a less than proportional change in output(s)].

Tables 2 and 3 indicate that some world-renowned ports such as Rotterdam, Hamburg and Antwerp have been found to be inefficient in production during the study period. This contrasts with the relatively high efficiency associated with smaller scale container ports such as Keelung and Colombo. Further investigation reveals that, during the period under study, infrastructure and equipment have remained relatively stable in the latter group of ports, while Rotterdam, Hamburg and Antwerp have invested actively in either or both their port facilities and/or infrastructure in order to increase and improve their container 
handling capability. The latter's relative inefficiency is likely to be caused, therefore, by the short-term overcapacity that is brought about by attempting to maintain or enhance productivity and increase competitiveness, rather than through any managerial shortcomings.

\section{Conclusions}

This paper applies DEA windows analysis in order to determine the efficiency of the world's leading container ports over time. This approach is advocated in favour of the commonly used cross-sectional data analysis. In a situation where a port has made a recent investment to achieve beneficial results in the future, or simply just as a result of random effects, the traditional cross-sectional approach may produce misleading results. This study concludes that the efficiency of the different container ports can fluctuate over time to different extents. Indeed, the empirical results reveal that substantial inefficiency exists in some container ports at some point in time. In consequence, this validates the necessity for using DEA windows analysis in preference to an analysis based upon cross-sectional data.

In order to determine the source of estimated inefficiency, the scale properties of container ports have been examined. Most ports exhibit constant returns to scale, indicating that production scale is not the main source of inefficiency. Although not conclusive, a qualitative analysis of some ports in the sample shows that the ports measured as being highly efficient appear to be those that do not invest actively over time. This contrasts with their low efficiency counterparts who invest actively in either port equipment or infrastructure in order to be competitive in the long-term.

This seems to imply that port competition and competitiveness may have a major and direct impact on the measured levels of relative efficiency within container ports. Some other possible reasons that may explain empirical estimates of inefficiency in port production include differences in port ownership or governance, locational attributes and the form and level of competition faced. A clearer assessment of the determinants of inefficiency may be gleaned from the application of the two-stage approach to DEA that utilises a Tobit regression model and allows for the incorporation of 'environmental variables' (see Coelli, Prasada Rao and Battese, 1998). This sort of further research, into the relationship between the measures of technical and scale efficiency derived herein and their potential determinants, is likely to shed light on the real reasons behind port (in)efficiency and yield important policy and strategic implications. As such, the analysis contained herein constitutes merely the beginning, rather than an end, of the research.

\section{$7 \quad$ References}

Ali, A. I. and Seiford, L. M. (1993) "The Mathematical Programming Approach to Efficiency Analysis," in H. Fried, C. A. K. Lovell and S. Schmidt (eds.), The Measurement of Productive Efficiency: Techniques and Applications. Oxford: Oxford University Press.

Ashar, A. (1997) “Counting the Moves," Port Development International, 13: 25-29. 
Banker, R. D., Charnes, A. and Cooper, W. W. (1984) "Some Models for Estimating Technical and Scale Inefficiencies in Data Envelopment Analysis," Management Science, 30: 1078-1092.

Bendall, H. and Stent, A. (1987) "On Measuring Cargo Handling Productivity," Maritime Policy and Management, 14: 337-343.

Charnes, A. Clark, C. T. Cooper, W. W. and Golany, B. (1985) "A Developmental Study of Data Envelopment Analysis in Measuring the Efficiency of Maintenance Units in the U.S. Air Forces," Annals of Operation Research, 2: 95-112.

Charnes, A., Cooper, W. W. and Rhodes, E. (1978) "Measuring the Efficiency of Decision Making Units," European Journal of Operational Research, 2: 429-444.

Coelli, T., Prasada Rao, D. S. and Battese, G.E. (1998) An Introduction to Efficiency and Productivity Analysis, Kluwer Academic Publishers, Boston.

Cooper, W. W., Seiford, L. M. and Tone, K. (2000) "Data Envelopment Analysis: A Comprehensive Text with Models, Applications, References and DEA-Solver Software," Boston: Kluwer Academic Publishers.

De Borger, B., Kerstens, K. and Costa, A. (2002) "Public Transit Performance: What does One Learn from Frontier Studies," Transport Reviews, 22: 1-38.

De Monie, G. (1987) "Measuring and Evaluating Port Performance and Productivity," UNCTAD Monographs on Port Management No. 6 on Port Management, Geneva: UNCTAD.

De Neufville, R. and Tsunokawa, K. (1981) "Productivity and Returns to Scale of Container Ports," Maritime Policy and Management, 8: 121-129.

Dowd, T. J. and Leschine, T. M. (1990), Container Terminal Productivity: A Perspective, Maritime Policy and Management, 17: 107-112.

Dyson, R. G. (2000) "Performance Measurement and Data Envelopment Analysis Ranking are ranks!" OR Insight, 13: 3-8.

Forsund, F. R. and Sarafoglou, N. (2002) "On the Origins of Data Envelopment Analysis," Journal of Productivity Analysis, 17: 23-40.

Kim, M. and Sachish, A. (1986) "The Structure of Production, Technical Change and Productivity in a Port," Journal of Industrial Economics, 35: 209-223.

Kumbhakar, S. C. and Lovell, C. (2000) Stochastic Frontier Analysis, Cambridge: Cambridge University Press.

Marlow, P. and Paixão, A. C. (2002) "Measuring Lean Ports Performance," Proceedings of the International Association of Maritime Economists Conference, November, Panama, 13-15. 
Martinez-Budria, E., Diaz-Armas, R., Navarro-Ibanez, M. and Ravelo-Mesa, T. (1999) "A Study of the Efficiency of Spanish Port Authorities Using Data Envelopment Analysis," International Journal of Transport Economics, XXVI: 37-253.

Notteboom, T., Coeck, C. and van den Broeck, J. (2000), Measuring and Explaining the Relative Efficiency of Container Terminals by Means of Bayesian Stochastic Frontier Models, International Journal of Maritime Economics, 2: 83-106.

Roll, Y. and Hayuth, Y. (1993) "Port Performance Comparison Applying Data Envelopment Analysis (DEA)," Maritime Policy and Management, 20: 153-161.

Seiford, L. M. and Thrall, R. (1990) "Recent Development in DEA: the Mathematical Programming Approach to Frontier Analysis," Journal of Econometrics, 46: 7-38.

Song, D. W., Cullinane, K. P. B \& Wang, T. (2003) "An Application of DEA Window Analysis to Container Port Production Efficiency," International Association of Maritime Economists Annual Conference, Busan, 3-5 September.

Tabernacle, J. B. (1995) "A Study of the Changes in Performance of Quayside Container Cranes," Maritime Policy and Management, 22: 115-124.

Talley, W. K. (1994) "Performance Indicators and Port Performance Evaluation," The Logistics and Transportation Review, 30: 339-352.

Talley, W. K., (1998) "Optimum Throughput and Performance Evaluation of Marine Terminals," Maritime Policy and Management, 15: 327-331.

Tongzon, J. L. (1995) "Determinants of Port Performance and Efficiency," Transport Research A, 29: 245-352.

Tongzon, J. L. (2001) "Efficiency Measurement of Selected Australian and Other International Ports Using Data Envelopment Analysis," Transportation Research A: Policy and Practice, 35: 113-128.

Tulkens, H. and Vanden Eeckaut, P. (1995) "Nonparametric Efficiency, Progress and Regress Measures for Panel-Data: Methodological Aspects," European Journal of Operational Research, 80: 474-499.

UNCTAD (1976) Port Performance Indicators, TD/B/ C.4/131/Supp.1/Rev.1, New York, U.S.: United Nations Conference on Trade and Development.

Valentine, V. F. and Gray, R. (2001) "The Measurement of Port Efficiency Using Data Envelopment Analysis," Proceedings of the $9^{\text {th }}$ World Conference on Transport Research, 22-27 July, Seoul, South Korea.

Wang, T., Song, D. W. and Cullinane, K. (2002) "The Applicability of Data Envelopment Analysis to Efficiency Measurement of Container Ports," Proceedings of the International Association of Maritime Economists Conference, Panama, 13-15 November. 